\title{
Synthesis and Characterization of Poly(NIPAM-co-AA) Polymers Possessing Perfluorinated Side Chains and Chemically Linked Pyrene Labels
}

\author{
Megh Raj Pokhrel ${ }^{* 1,2}$ and Stefan H. Bossmann ${ }^{1}$ \\ ${ }^{1}$ Central Department of Chemistry, Tribhuvan University, Kathmandu, Nepal, ${ }^{2}$ Department of \\ Chemistry, Kansas State University, 213 CBC Building Manhattan, KS, 66506-0401, USA \\ Email:meghraj11@hotmail.com
}

\begin{abstract}
The synthesis of Poly(n-isopropylacrylamide-co-acrylic acid)/-Poly(NIPAM-co-AA) polymers featuring perfluorinated side chains as well as chemically linked pyrene fluorescence labels has been reported. The resulting polymers have been characterized with the aid of UV/VIS, FTIR spectroscopy and Gel permeation chromatography.
\end{abstract}

Keywords: Polymers, Poly(n-isopropylacrylamide-co-acrylic acid)/-Poly(NIPAM-co-AA), Pyrene, photochemical sensor, gel permeation chromatography

\section{Introduction}

The synthesis and characterization of high molecular weight, water soluble polymers containing hydrophobic side chains are of high interest for the following reasons: Water soluble polymers which feature chemically linked hydrophobic units are simple models for the interaction of proteins with the solvent water as well as with other polymeric functions. The influence of the hydrophobic centers on the conformation and dynamics of the macromolecules can be elucidated in model system with higher precision $^{1,2}$. Consequently, the physical properties of these model systems permit their straight-forward applications in systems of technical importance in a straight forward manner. In the work reported here, we introduced chemically linked perfluorinated side chains as a profound example of a hydrophobic function in the water soluble Poly (NIPAM -co-AA) polymer ${ }^{3}$.

The development and application of photochemical sensors which rely on changes of the dynamics and conformation of polymers offers new opportunities for the production of inexpensive and long term stable sensors for gases and ions of environmental importance ${ }^{4}$. The detection of these changes as a function of the environment impact can be achieved using chemically attached fluorescence labels ${ }^{5}$. We report here the synthesis and characterization of hydrophobically modified poly(NIPAM-co-AA) polymers which feature chemically linked 1aminomethyl-pyrene as fluorescence labels. The application of the well-established pyrene fluorophore permits the detection of the polymer dynamics by means of the separate

\section{* Corresponding author}


measurement of the monomer and excimer emission. Whereas monomer emission arises from isolated pyrene units in the photochemically excited singlet state, excimer emission occurs from an excited dimmer, formed by an excited and ground state pyrene molecule ${ }^{6}$.

\section{Experimental Methods}

\section{Materials}

All commercial chemicals (i.e. $\mathrm{N}$-isopropylacrylamide, acrylic acid, 2,2'-azoisobutyronitrile, tert-butyl alcohol, tetrohydrofuran, n-hexane, diethyl ether, 1-aminomethyl-pyrene, 1-bromoperfluoro-n-octane, sodium carbonate, dimethylformamide) were from Aldrich Chemical Co. unless otherwise mentioned, and were used without purification. Figure 1 shows the structure of the employed polymer and other compounds.

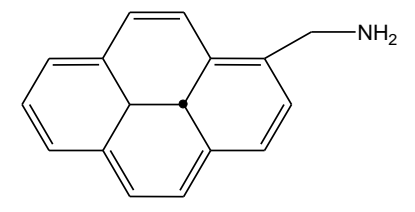

1-aminomethyl-pyrene<smiles>FC(F)CCCCCCCCC(F)F</smiles>

1-bromo-perfluoro-n-octane

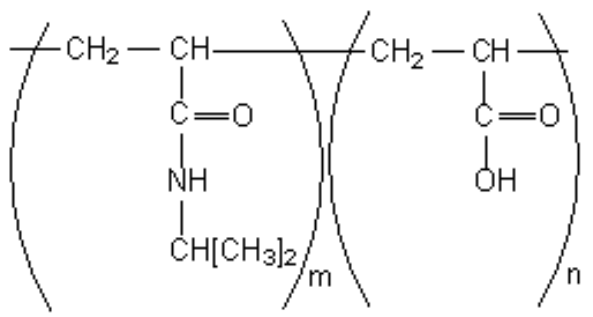

Poly(NIPAM-co-AA)

Figure 1: $\quad$ Structure of employed polymer and other compounds

Synthesis procedures and characterization techniques

The starting material Poly(NIPAM-co-AA) was synthesized according to our previous published report. ${ }^{3}$

Synthesis of Poly(NIPAM-co-AA) featuring perfluorinated side chains

An amount (3.0 g) of Poly(NIPAM-co-AA) was dissolved in $50 \mathrm{~mL}$ anhydrous DMF and the solution stirred for an hour. An amount of $0.0 .68 \mathrm{~g}(0.001 \mathrm{~mol})$ and $1.38 \mathrm{~g}(0.002 \mathrm{~mol})$ of 1bromo-perfluoro-n-octane $\left(\mathrm{C}_{8} \mathrm{~F}_{17} \mathrm{Br}, \mathrm{m}=498.9 \mathrm{~g}\right.$ mol-1) and $2.0 \mathrm{~g}$ of $\mathrm{Na}_{2} \mathrm{CO}_{3}$ were added and the reaction mixture was allowed to react for $15 \mathrm{~h}$ at $120^{\circ} \mathrm{C}$. The resulting polymer solution was filtered warm in order to remove the inorganic salts. After being cooled to $10{ }^{\circ} \mathrm{C}, 80 \mathrm{~mL}$ of 
diethyl ether was added dropwise and the polymer precipitated slowly. After being stirred for 1 $\mathrm{h}$, the polymer was filtered off and dissolved again in $30 \mathrm{~mL}$ of DMF. Then again, $80 \mathrm{~mL}$ of diethyl ether was added and the polymer was collected. This procedure was repeated one additional time. Copolymers, Poly(NIPAM-co-AA) $-\mathrm{C}_{8} \mathrm{~F}_{17}$ having mol \% 95.3 and 90.8 of NIPAM, 2.2 and 4.2 of acrylic acid and 2.5 and $5 \mathrm{~mol} \%$ of $\mathrm{C}_{8} \mathrm{~F}_{17}$ were synthesized using this procedure. The yield was about $2.4-2.5 \mathrm{~g}$

Synthesis of Poly(NIPAM-co-AA) featuring perfluorinated side chains and chemically linked pyrene

An amount $0.010 \mathrm{~g}\left(3.73 \times 10^{-5} \mathrm{~mol}\right)$ 1-aminomethyl-pyrene hydrochloride $\left(\mathrm{C}_{17} \mathrm{H}_{14} \mathrm{NCl}, \mathrm{m}\right.$ $=267.7 \mathrm{~g} / \mathrm{mol}$ ) was dissolved in $10 \mathrm{~mL}$ bidistilled water. The $\mathrm{pH}$ of the solution was adjusted to 10.0 using sodium hydroxide solution $(0.01 \mathrm{M})$. 1-aminomethyl-pyrene was extracted employing $20 \mathrm{~mL}$ of diethyl ether.

An amount (3.0 g) of Poly(NIPAM-co-AA) was dissolved in $50 \mathrm{~mL}$ anhydrous DMF and the solution stirred for an hour. An amount $0.03 \mathrm{~g}\left(1.15 \mathrm{x} 10^{-4} \mathrm{~mol}\right)$ of dicyclohexylcarbodiimide (DCC, $\mathrm{C}_{13} \mathrm{H}_{22} \mathrm{~N}_{2}, \mathrm{~m}=206.3 \mathrm{~g} / \mathrm{mol}$ ) and the $20 \mathrm{~mL}$ of diethyl ether containing 1 aminomethyl-pyrene were added and the mixture, which was constantly purged with nitrogen and allowed to react for $2 \mathrm{~h}$ at $60^{\circ} \mathrm{C}$. Then $0.68 \mathrm{~g}(0.001 \mathrm{~mol})$ and $1.38 \mathrm{~g}(0.002$ $\mathrm{mol})$ of 1-bromo-perfluoro-n-octane $\left(\mathrm{C}_{8} \mathrm{~F}_{17} \mathrm{Br}, \mathrm{m}=498.9 \mathrm{~g}\right.$ mol-1) and $2.0 \mathrm{~g}$ of $\mathrm{Na}_{2} \mathrm{CO}_{3}$ were added and the reaction mixture was allowed to react for $15 \mathrm{~h}$ at $120{ }^{\circ} \mathrm{C}$. The resulting polymer solution was filtered warm in order to remove the inorganic salts. After being cooled to $10{ }^{\circ} \mathrm{C}$, $80 \mathrm{~mL}$ of diethyl ether was added dropwise and the polymer precipitated slowly. After being stirred for $1 \mathrm{~h}$, the polymer was filtered off and dissolved again in $30 \mathrm{~mL}$ of DMF. Then again, $80 \mathrm{~mL}$ of diethyl ether was added and the polymer was collected. This procedure was repeated one additional time. The Yield was about 2.4-2.6 g

The characterization of the polymers was performed using the following techniques:

The pyrene content of the novel polymer material was determined using UV/VIS spectroscopy (Hewlett-Packard 8452A diode array spectrometer with HP8452 Win system software based on Windows 3.1). The infrared spectra were measured with solid samples on a Hartmann and Braun FTIR spectrometer using Bomem Grams/32 software (version 4.04) for data processing. Samples were prepared by mixing the pulverized polymer with spectrograde potassium bromide in a ratio of approximately 1:5 and pressing a tablet using a hydraulic press at approximately 200 bar. Polymers that could not be pulverized because of their plastic nature were dissolved in spectrograde chloroform. The saturated solution was applied on a $\mathrm{KBr}$ tablet and the solvent was evaporated leaving a polymer film on the tablet. IR spectra were recorded in a wavenumber range from 3600 to $500 \mathrm{~cm}^{-1}$.

\section{Gel permeation chromatography}

The gel permeation chromatography (GPC) experiments were carried out employing an HP TSK-AC/4000 SW; $7.5 \times 300 \mathrm{~mm}$ column. An aqueous solution of $\mathrm{Na}_{2} \mathrm{SO}_{4}\left(0.10 \mathrm{M}^{-1}\right)$ and $\mathrm{Na}_{2} \mathrm{HPO}_{4}\left(0.10 \mathrm{M}^{-1}\right)$ was used as eluent. The $\mathrm{pH}$ of 7 was adjusted using diluted $\mathrm{H}_{3} \mathrm{PO}_{4}$. The polymers were detected at a wavelength of $220 \mathrm{~nm}$. Commercially available polyacrylic acid standards (Aldrich) were used for GPC calibration. 


\section{Results and Discussion}

Synthesis of Poly(NIPAM-co-AA) possessing hydrophobic side chains as well as chemically linked pyrene, (Poly(NIPAM-co-AA)- $\left.C_{8} F_{17}-P Y\right)$

Poly(NIPAM-co-AA) was used as starting material for the synthesis of both Poly (NIPAMco-AA) $-\mathrm{C}_{8} \mathrm{~F}_{17}$ and Poly(NIPAM-co-AA) $-\mathrm{C}_{8} \mathrm{~F}_{17}-\mathrm{PY}$ polymers. The labeled copolymers were prepared by the reaction of 1-aminomethylpyrene and 1-bromoperfluoro-n-octane with a copolymer of $\mathrm{N}$-isopropylacrylamide and acrylic acid, Poly(NIPAM-co-AA). 1-Aminomethyl-

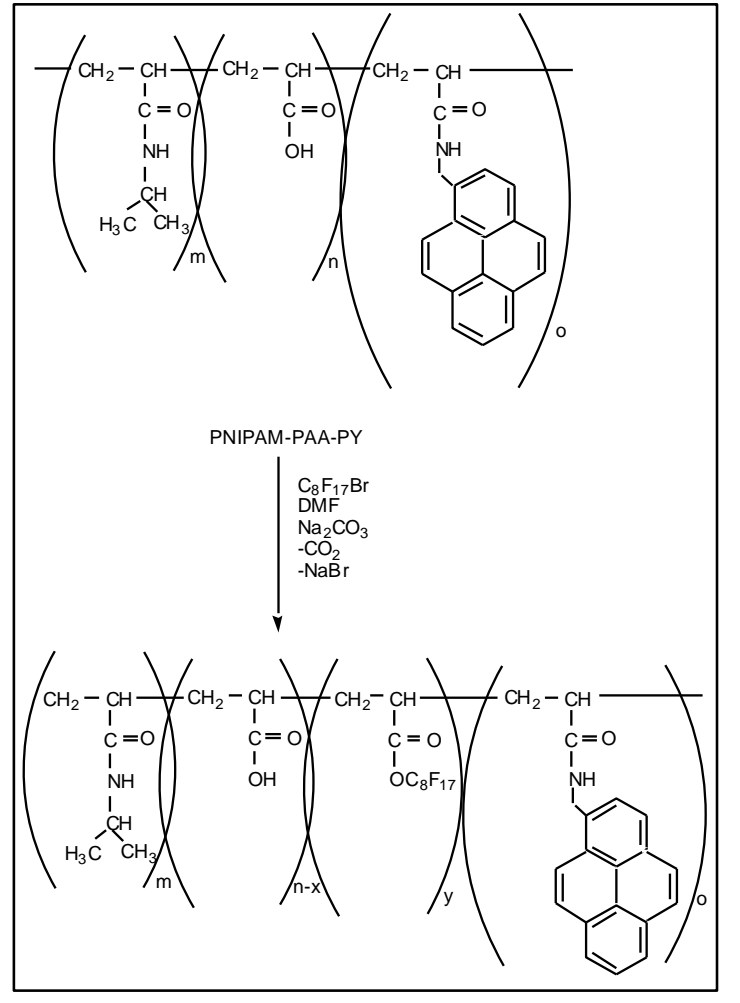

Figure 2: Labeling of copolymer of the Poly(NIPAM-co-AA) with 1-aminomethyl pyrene and 1-bromo-perfluoro-n-octane by the formation of an amide bond and ester linkage respectively with carboxylic acid function of the copolymer.

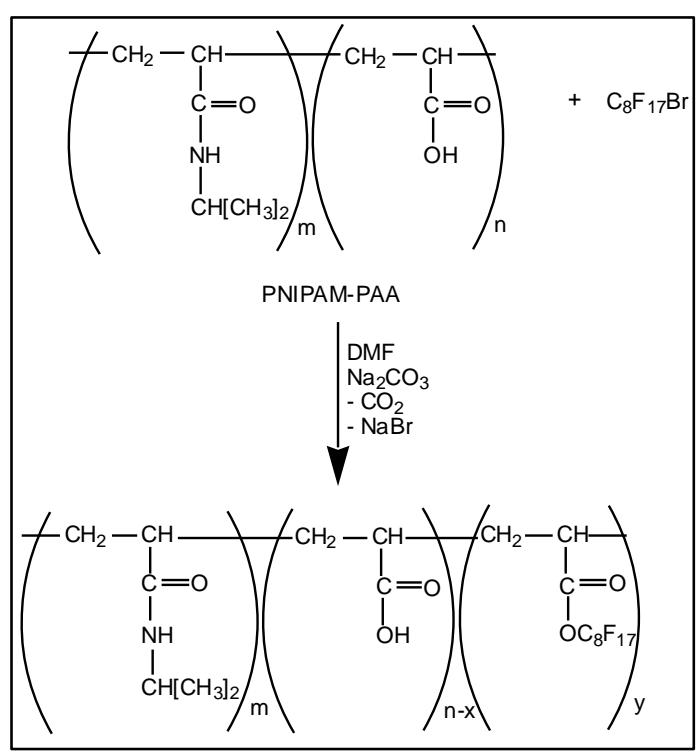

Figure 3: Labeling of Poly(NIPAM-co-AA) with $C_{8} F_{17}$

pyrene has been attached to the carboxylic acid functions of the copolymer by the formation of an amide bond ${ }^{7}$. Figure 2 and 3 show the synthesis of Poly(NIPAM-co-AA)- $\mathrm{C}_{8} \mathrm{~F}_{17}-\mathrm{PY}$.

The formation of an amide bond between carboxylic acid group of the copolymer and 1aminomethyl-pyrene was accomplished using dicyclohexylcarbodiimde (DCC) as agent for the removal of water in dimethylformamide (DMF) as solvent ${ }^{8}$. The hydrophobic side chains were 
introduced by the reaction of carboxylic acid group of the copolymer and 1-bromo-perfluorooctane in DMF. Sodium carbonate was added in order to trap the $\mathrm{HBr}$ formed during synthesis. The copolymers were purified by repeated precipitations of DMF solutions into diethyl ether, a non-solvent for copolymers but a good solvent of all the monomers.

\section{Determination of pyrene content}

The pyrene content of the novel polymers has been determined by using UV/VISspectroscopy $\left(\varepsilon(334 \mathrm{~nm})=42500[\mathrm{~mol} \mathrm{~cm} \mathrm{~L}]^{-1}\right]^{9}$ and it was found to be in between 0.20 and $0.47 \mathrm{~mol} \%$ of pyrene. The UV absorption spectra of pyrene labeled Poly(NIPAM-co-AA) is shown in Figure 4. The three characteristics absorption bands of aminomethyl-pyrene are located at 312, 326 and $342 \mathrm{~nm}$.

\section{FTIR-Spectroscopy}

Infra-red spectra of fluorinated and non-fluorinated polymers (the samples without pyrene) were recorded in order to determine the differences in the spectra due to the hydrophobic $-\mathrm{C}_{8} \mathrm{~F}_{17}$ side chains. The spectra were normalized in order to adjust the intensities and the spectrum of the fluorinated polymer was superimposed to the non-fluorinated one.

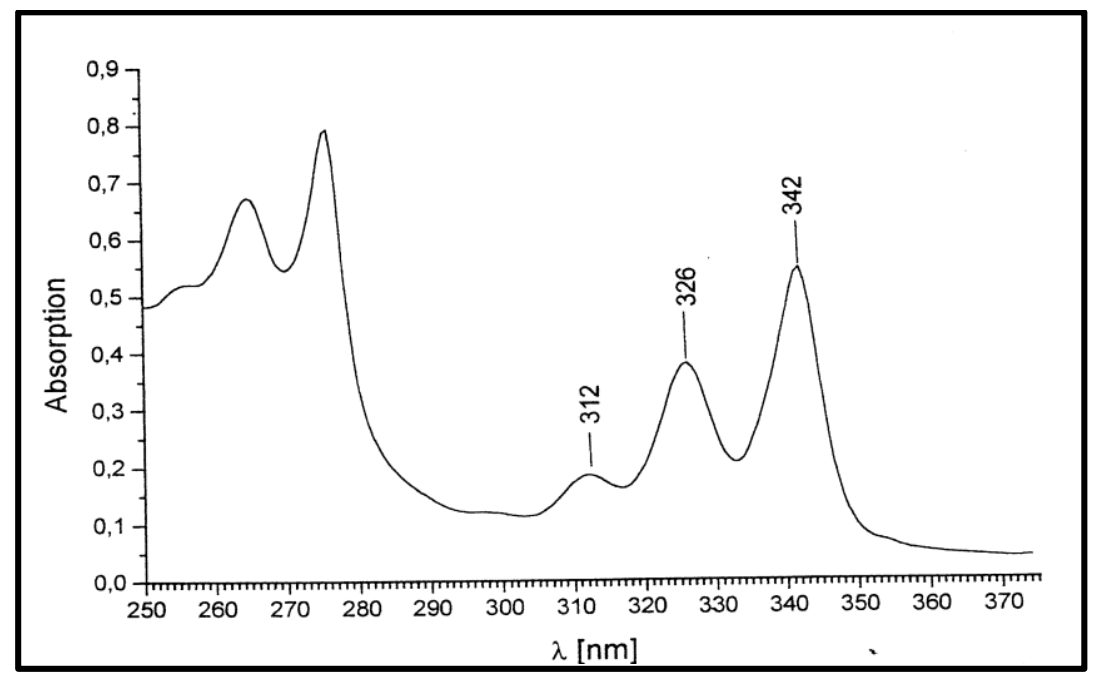

Figure 4: UV absorption spectrum of pyrene labeled Poly(NIPAM-co-AA)

Figure 5 shows the superimposed spectra of the respective polymers for comparison. Apart from little differences in the intensity, the spectra are very similar. However, the fluorinated polymer has some absorption peaks that do not appear in the spectrum of the corresponding non-fluorinated polymer. The fluorinated polymer spectrum shows a weak peak at $665 \mathrm{~cm}^{-1}$ and a strong one around $752 \mathrm{~cm}^{-1}$. They belong to the $-\mathrm{CF}_{3}$ group of the per-fluorinated chains. The bands of $-\mathrm{CF}_{2}$ should appear between $1250 \mathrm{~cm}^{-1}$ and $1050 \mathrm{~cm}^{-1}$ but they may be shifted to lower wavenumbers due to the $\mathrm{C}=\mathrm{O}$ group of the ester. 
Table 1: $\quad$ Molecular weight and polydispersities of polymers

\begin{tabular}{|l|c|c|c|}
\hline \multicolumn{1}{|c|}{ Polymers } & $\mathrm{M}_{\mathrm{N}}$ & $\mathrm{M}_{\mathrm{W}}$ & $\mathbf{P}_{\mathbf{D}}$ \\
\hline Poly(NIPAM-co-AA) & 90,800 & 131,700 & $\mathbf{1 . 4 5}$ \\
\hline Poly(NIPAM-co-AA)-C ${ }_{8} \mathrm{~F}_{17}$ & 103,000 & 156,500 & $\mathbf{1 . 5 2}$ \\
\hline Poly(NIPAM-co-AA)-C $\mathbf{C}_{\mathbf{8}} \mathbf{F}_{\mathbf{1 7}}$-PY & $\mathbf{1 0 3 , 5 0 0}$ & $\mathbf{1 5 6 , 5 0 0}$ & $\mathbf{1 . 5 2}$ \\
\hline
\end{tabular}

This would be a possible reason for the two little peaks appearing at $1031 \mathrm{~cm}^{-1}$ and 1017 $\mathrm{cm}^{-1}$ in the spectrum of the Poly(NIPAM-co-AA)- $\mathrm{C}_{8} \mathrm{~F}_{17}$ (marked with a circle in the Figure 5). Three bands of carboxylic acid appear between $3000 \mathrm{~cm}^{-1}$ and $2750 \mathrm{~cm}^{-1}$ for both, the fluorinated and non-fluorinated polymer. The band around $2350 \mathrm{~cm}^{-1}$ belongs to atmospheric $\mathrm{CO}_{2}$. The broad peak at $3300 \mathrm{~cm}^{-1}$ in the spectra of the fluorinated polymers belongs to the secondary amide of NIPAM. In the same spectral region $\left(3250 \mathrm{~cm}^{-1}-3550 \mathrm{~cm}^{-1}\right)$ a very broad band can be seen in the spectra of non-fluorinated polymer which overlaps the NIPAM band. It is due to residual water in the polymer without fluorine. In fact, the fluorinated polymer obviously contains less water because of its hydrophobic per-fluorinated alkyl chains ${ }^{10}$. This is the reason for which the amide peak of NIPAM can only be seen in the fluorinated polymer.

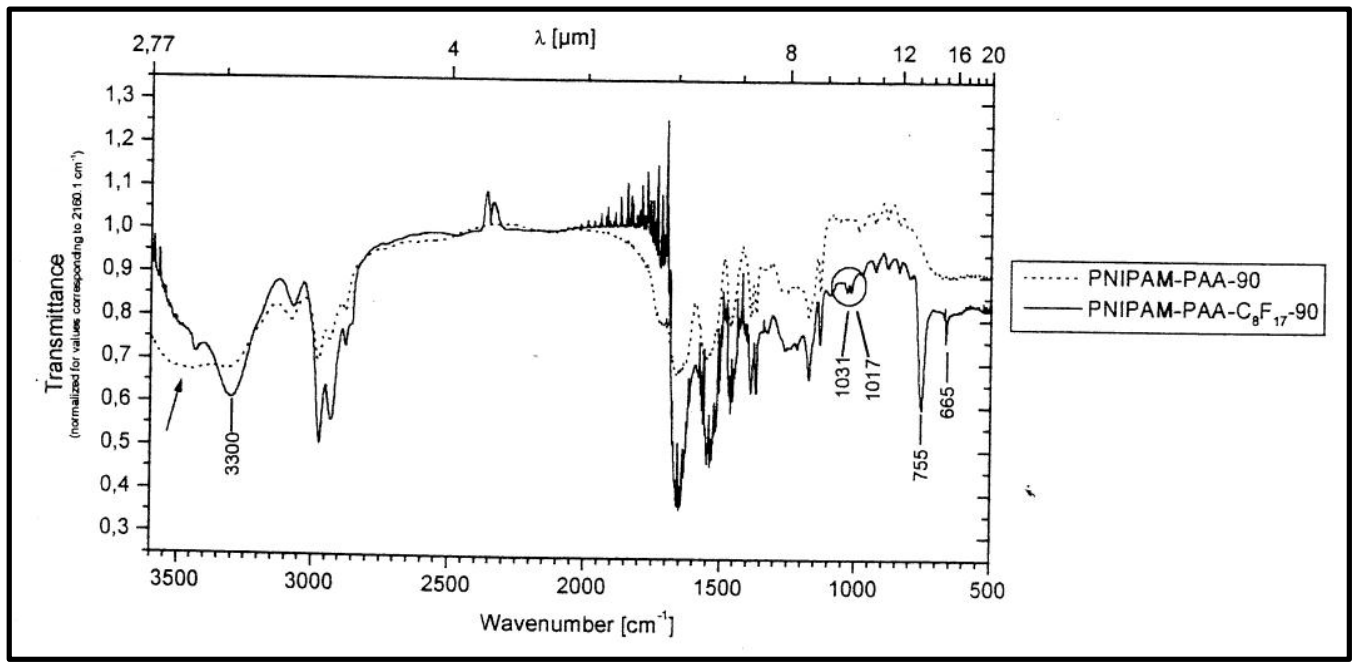

Figure 5: FTIR spectrum of Poly(NIPAM-co-AA) and Poly(NIPAM-co-AA)- $C_{8} F_{17}$

\section{Gel permeation chromatography $(G P C)$}

The weight averaged $[\mathrm{Mw}]$ and number average $[\mathrm{MN}]$ and polydispersities of the synthesized polymers that were determined by means of GPC are summarized in Table 1. It is 
apparent that the fluorinated polymer shows a higher molecular weight in comparison to the non-fluorinated polymer. It means that the $-\mathrm{COOH}$ groups of the polymer have been reacted with perfluorinated groups to form the hydrophobically modified copolymers.

\section{Conclusion}

The synthesis of Poly(NIPAM-co-AA) polymers featuring per-fluorinated side chains and chemically linked pyrene labels has been reported. 1-Aminomethyl-pyrene has been attached to the copolymer by the formation of an amide bond and the hydrophobic units by means of an ester linkage employing 1-bromo-perfluoro-n-octane. The labeling of the copolymers with 1aminomethyl-pyrene has been confirmed with the help of UV/VIS spectroscopy. Infrared spectroscopy has indicated the presence of fluorinated alkyl chains in the polymer. The pyrene content of the labeled polymer was determined by UV/VIS spectroscopy and the values were found to be in between 0.20 and 0.47 mol- $\%$ of pyrene.

\section{Acknowledgements}

The authors would like to thank Prof. Dr. A.M. Braun of the Institute of Environmental Analysis Technology at the Engler-Bunte-Institute, University of Karlsruhe for his valuable advice and for the use of his instrumentation. Financial support from the Research Foundation of Baden-Wurttemberg, the German Research Foundation (DFG, BO 1060/111-3) and the Funds of the German Chemical Industry (FCI) are gratefully acknowledged.

\section{References}

1. S. Panksem, J.K.Thomas, M.J. Snowden, B. Vincent, Langmuir, 1994, 10, 3023.

2. J. Pilar, J. Labsky, Macromolecules, 1994, 27, 3977.

3. M.R. Pokhrel, S.H. Bossmann, J. Nep. Chem. Soc. 1997, 16, 13.

4. K. Hosoya, E.Sawada, K. Kimata, T. Araki, N. Tanaka, J.M.J. Frechet, Macromolecules, 1994, 14, 3973.

5. F.M. Winnik, M.F. Ottaviani, S.H. Bossmann, W. Pan, M.Garcia Garibay, N.J. Turro, J. Phys. Chem. 1993, 97, 12998.

6. N.J. Turro, Modern Molecular Photochemistry, University Science Books, 1991, Mill Valley, CA.

7. M.R. Pokhrel, S.H. Bossmann, J. Phys. Chem. B 2000, 104, 10, 2215.

8. N. Turro, I. Khudyakov, S.H. Bossmann, D. Dwyer, J. Phys. Chem. 1993, 91, 1138.

9. R. A Friedel, M. Orchin, Ultraviolet Spectra of Aromatic Compounds; Wiley \& Sons: New York, 1951, p. 702

10. J. Dean, Lange's Handbook of Chemistry, $14^{\text {th }}$ ed. 766, New York, McGraw-Hill. 